\title{
Fungicidal Activity Plus Reservoir Effect Allow Short Treatment Courses with Terbinafine in Tinea pedis
}

\author{
M. Schäfer-Korting ${ }^{a} \quad$ C. Schoellmann ${ }^{b} \quad$ H.C. Korting ${ }^{b}$ \\ a Department of Pharmacy (Pharmacology and Toxicology), Freie Universität Berlin, Berlin, and \\ ${ }^{b}$ Department of Dermatology and Allergology, Ludwig-Maximilians-Universität, Munich, Germany
}

\section{Key Words}

Terbinafine $\cdot$ Tinea pedis $\cdot$ Topical therapy $\cdot$ Short-term therapy $\cdot$ Fungicidal activity $\cdot$ Reservoir effect

\begin{abstract}
Terbinafine, a synthetic allylamine, exerts fungicidal activity against dermatophytes, the causative pathogens of tinea pedis. As proven in numerous clinical trials, tinea pedis can be effectively and safely treated by topical terbinafine. In fact, a 1-week application of terbinafine 1\% cream eradicated fungal pathogens at least as effectively as 4-week treatment courses with topical azole derivative antifungals and showed lower relapse rates. A new innovative single-application formulation of terbinafine $1 \%$ in a film-forming solution produces a high concentration gradient on the skin surface and enables a prolonged (up to 13 days) exposure of the skin to terbinafine. High drug penetration into the skin results in an otherwise not obtained drug reservoir in the horny layer, the location of dermatophytes in tinea pedis. Although azole antimycotics can also effectively penetrate into the horny layer of the skin, short-term therapy might not be feasible due to its primarily fungistatic activity against dermatophytes. Thus, we conclude that the high efficacy of short-term treatment with terbinafine in patients with tinea pedis is possible due to its fungicidal activity coupled with a distinct reservoir formation in the upper layers of the epidermis.

Copyright $\odot 2008$ S. Karger AG, Base
\end{abstract}

\section{KARGER}

Fax +41613061234 E-Mail karger@karger.ch www.karger.com
(C) 2008 S. Karger AG, Base

$1660-5527 / 08 / 0214-0203 \$ 24.50 / 0$

Accessible online at:

www.karger.com/spp

\section{Introduction}

Topical antifungal therapy is well accepted for the management of cutaneous dermatophyte infections [1]. Terbinafine, a synthetic allylamine, exerts a potent broadspectrum fungicidal activity by inhibiting squalene epoxidase. The interference with sterol synthesis is selective for fungal enzymes and has little impact on the cholesterol biosynthesis of mammals [2]. Various topical forms of terbinafine (Lamisil ${ }^{\circledR}$; cream, gel and spray solution) have been approved and are available for the treatment of dermatomycoses in many countries. A 1-week treatment with once daily application for interdigital-type tinea pedis has been approved for these topical forms in European countries. Most recently, a new single-application formulation was specifically developed and approved for tinea pedis - terbinafine $1 \%$ in a film-forming solution (FFS) (Lamisil Once, Lamisil Pedisan Once). Here we describe the scientific rationale that allows a single-application therapy in cutaneous mycosis. This takes into account the specific features of terbinafine and the new FFS.

\section{Antifungal Activity of Terbinafine}

In approximately $98 \%$ of the cases, dermatophytes are the pathogens causing fungal infections of the foot [3-6]. In vitro susceptibility tests have shown that terbinafine exerts primarily fungicidal activity against dermato- 
Fig. 1. Distribution of the minimum inhibitory concentrations (MIC) of 6 antimicrobial agents against 48 Trichophyton rubrum and T. mentagrophytes strains isolated from infected nail plates in 7 dermatological centers from various parts of Germany. $\mathbf{\square}=$ T. rubrum; $\square=T$. mentagrophytes [9]. a Griseofulvin. b Ketoconazole. c Itraconazole. d Fluconazole. e Terbinafine. f Ciclopiroxolamine.
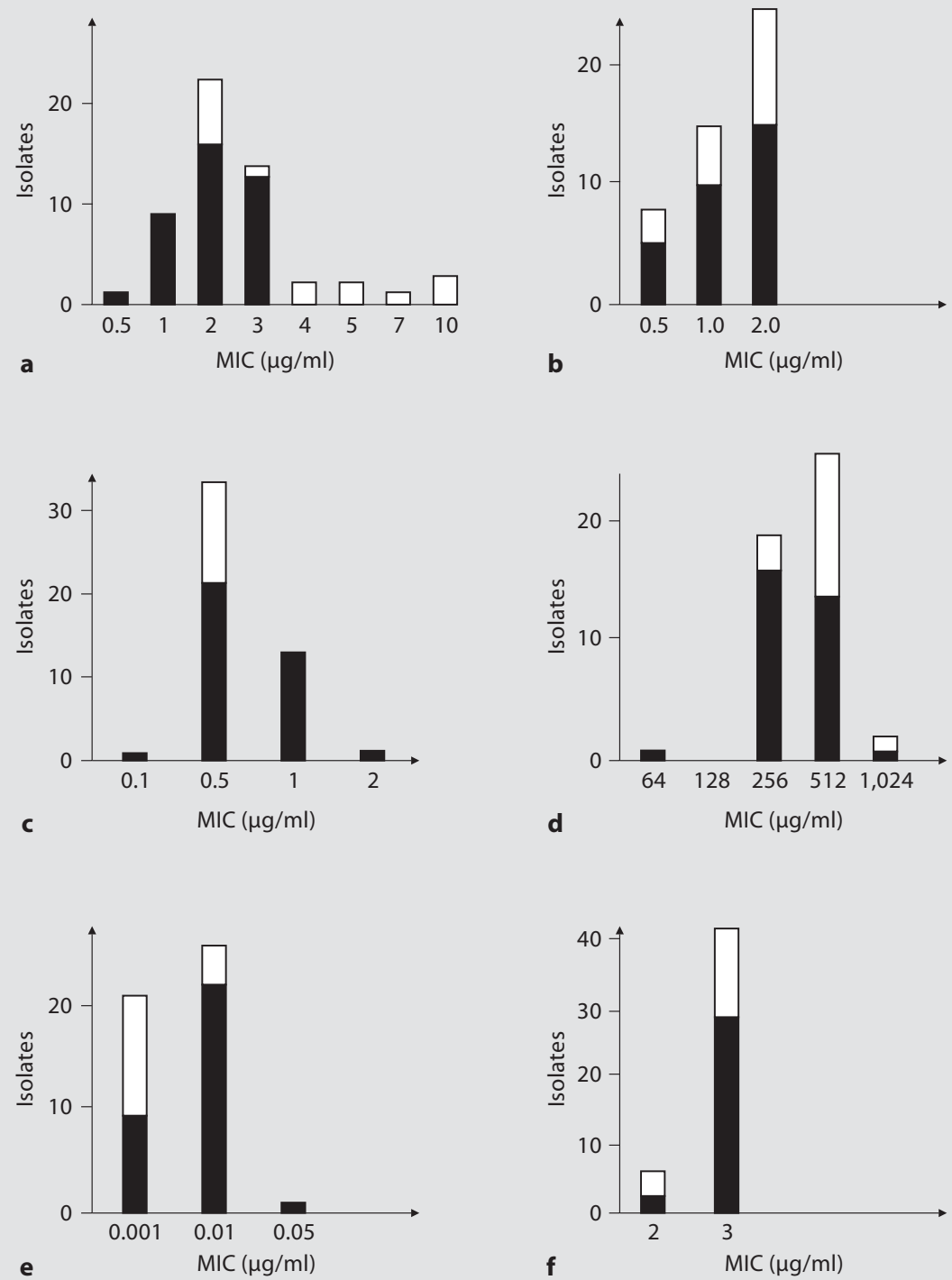

phytes, Aspergillus spp., Scopulariopsis brevicaulis, Blastomyces dermatitidis, Histoplasma capsulatum and Candida parapsilosis, while a fungistatic activity is seen against $C$. albicans [7]. In vitro terbinafine is most active (fig. 1) against dermatophytes such as Trichophyton, Microsporum and Epidermophyton spp. [8], with minimum inhibitory concentrations of $0.001-0.05 \mu \mathrm{g} / \mathrm{ml}$ [9-11]. For terbinafine, the minimum fungicidal concentrations for dermatophytes are comparable to its minimum inhibitory concentrations $[10,12]$. Thus, terbinafine eliminates fungi at concentrations that are several magnitudes below those found with azole derivatives, which exert fungistatic ac- tivity, the minimum inhibitory concentration range mainly spreading from 0.1 to $>10 \mu \mathrm{g} / \mathrm{ml}$. In fact, the in vitro activity of terbinafine against dermatophytes as a rule exceeds the activity of other antifungal agents $[9,13]$.

\section{Efficacy of Terbinafine in Comparison with Placebo and Azole Antifungal Agents}

A number of placebo-controlled and active comparator (including topically applied antifungal azoles) trials have examined the efficacy of topical terbinafine in pa- 
tients with tinea pedis. A review of 8 placebo-controlled trials reported topical terbinafine therapy to produce mycological cure rates significantly superior to those found with placebo ranging from 81 to $100 \%$ within $6-8$ weeks [13]. In these clinical studies, 703 patients with tinea pedis were treated with terbinafine $1 \%$ cream, solution, gel or placebo once or twice daily for 1-4 weeks, with 1-week application being the most common mode of use. Different treatment periods and frequencies resulted in similar mycological and clinical cure rates [14-21].

Several well-controlled trials comparing the efficacy of topical terbinafine to topical antifungal azoles in 1,523 patients with tinea pedis have been published [for review see 22,23$]$. Terbinafine $1 \%$ cream or solution was applied once or twice daily for 1 or 2 weeks, while azole-containing topicals were used for 4 weeks in most studies. In 1 study, bifonazole cream was applied for 2 weeks [24], in another oxiconazole cream was applied for 2 weeks [25]. Mycological response to the therapy was evaluated by culture up to 11 weeks after the end of treatment. These studies show terbinafine has similar efficacy compared to clotrimazole, miconazole, bifonazole or oxiconazole but with shorter duration of treatment. As the treatment duration with terbinafine was shorter in most cases, this suggests its superior effectiveness [26-31]. Furthermore, some studies have described a higher clinical cure rate following terbinafine as compared to the azole treatment despite shorter duration of treatment [25-28, 32]. Most interestingly, the mycological and clinical cure rates continued to increase after the end of the 1-week terbinafine treatment [25-28]. Relapse/reinfection rates (made evident by reversion to positive culture) were less frequent in the terbinafine groups than in patients receiving clotrimazole. Approximately $30 \%$ of the 'cured' patients had a relapse/reinfection within 8 weeks after treatment with a 4-week course of clotrimazole cream. By comparison, $<10 \%$ of the cured patients treated with terbinafine cream for 1 week had relapse/reinfection by 11 weeks after treatment [26].

Most recently, a single application using a new terbinafine $1 \%$ FFS was shown to be effective in the treatment of tinea pedis as demonstrated by 2 vehicle-controlled double-blind studies. In a dose-finding study of $536 \mathrm{pa}-$ tients with tinea pedis, terbinafine $1 \%$ FFS resulted in a mycological cure rate of $84 \%$ compared to only $27 \%$ with the vehicle [33]. In a second study, 190 patients with interdigital-type tinea pedis were treated with terbinafine $1 \%$ FFS and 83 with the vehicle. After 6 weeks, mycological cure was achieved in $72 \%$ of the patients receiving terbinafine $1 \%$ FFS compared to $21 \%$ of the patients who received the vehicle [34]. The relapse/reinfection rate of cured patients (12.5\%) 3 months after the end of the single-dose therapy was similar to that previously seen when using terbinafine $1 \%$ cream for 7 days $(9.3 \%)[26,34]$. Thus, in both studies terbinafine $1 \%$ FFS was significantly superior over the vehicle and the cure rates were close to those with 7 -day treatment of terbinafine $1 \%$ cream applied once or twice daily [35].

Three systematic reviews report a low incidence of side effects for both terbinafine and the azoles [13, 22, 23]. Similarly, single-application terbinafine $1 \%$ FFS has also shown a low incidence of side effects $[34,36]$. Thus, terbinafine is as effective and safe as azoles but is superior with regards to effectiveness based on its remarkably short treatment duration (i.e. 1 week for cream, gel and solution; single application for FFS).

\section{Effect of Terbinafine over Time}

Clinical studies have shown that terbinafine provides continued increase in cure rates for days to weeks after discontinuation of treatment in patients with tinea pedis. This holds true both for the oral and topical route of application. An early placebo-controlled study evaluating the efficacy of oral terbinafine (125 mg b.i.d for 6 weeks) for moccasin-type tinea pedis showed a complete cure in $59 \%$ of the patients at the end of therapy and $65 \%$ after an additional 2 weeks [37]. As a result, significantly shorter treatment periods were subsequently tested. In fact, oral administration of terbinafine $250 \mathrm{mg} /$ day for 2 weeks induced a complete cure within 4-6 weeks after the end of the therapy in $80-90 \%$ of the patients with dermatophyte infections of the feet or hands [for review see 8].

An increase in cure rates after treatment cessation has also been observed following topical application of terbinafine. The application of terbinafine $1 \%$ cream twice daily for 1 week resulted in the eradication of dermatophytes in $93.5 \%$ within 4 weeks after the end of treatment, and this rate increased to $97.2 \%$ at 6 weeks after treatment [27]. In a randomized controlled trial of 100 patients with tinea pedis treated with terbinafine $1 \%$ cream once daily for 7 days, mycological cure was reported in $50 \%$ of the patients immediately following discontinuation of treatment, which increased to $91.4 \%$ at 7 weeks after treatment [16]. The authors concluded that the increasing efficacy of terbinafine after the end of the treatment period can be accounted for not only by the fungicidal effect but also in particular by its favorable pharmacokinetic characteristics of substantial and rapid penetration into the stra- 
Table 1. Mean stratum corneum pharmacokinetics of terbinafine following a single application of $1 \%$ terbinafine FFS and the cream $\left(50 \mu \mathrm{g} / \mathrm{cm}^{2}[36]\right)$

\begin{tabular}{lll}
\hline & $\begin{array}{l}1 \% \text { terbinafine } \\
\text { FFS } \\
\text { (single application) }\end{array}$ & $\begin{array}{l}1 \% \text { terbinafine } \\
\text { cream } \\
\text { (single application) }\end{array}$ \\
\hline $\mathrm{C}_{\max }, \mathrm{ng} / \mathrm{cm}^{2}$ & $4,952^{* *}$ & $1,951^{\mathrm{a}}$ \\
$\mathrm{t}_{1 / 2}, \mathrm{~h}$ & $162^{*}$ & $68^{*}$ \\
AUC $(0-168 \mathrm{~h}), \mathrm{ng} \times \mathrm{h} / \mathrm{cm}^{2}$ & $104,178^{* *}$ & $35,770^{\mathrm{a}, * *}$ \\
\hline
\end{tabular}

$\mathrm{C}_{\max }=$ Mean peak concentration. ${ }^{*} \mathrm{p}=0.0004$ (Wilcoxon signed rank test); ${ }^{* *} \mathrm{p}<0.0001$ (Student's t test).

a Extrapolated data.

tum corneum and remanence in the tissue for a long time after discontinuation of treatment. This is particularly evident with the new terbinafine formulation, where the cure rates continue to increase for up to 6 weeks after a single application [36].

\section{Skin and Plasma Pharmacokinetics of Terbinafine}

Based on several studies conducted in humans [36, $38-41]$ and animals $[42,43]$, it has been noted that terbinafine accumulates in the skin after topical or oral application and persists at high concentrations up to several weeks after discontinuation of drug application. Being highly lipophilic, terbinafine attaches to keratinocytes and thereby remains in the stratum corneum for a long time [44]. Terbinafine also accumulates in the nails, hair, dermis/epidermis and in subcutaneous fat tissues [39, 40] after oral treatment. Long-term retention in the skin is also evident after topical application of terbinafine, while the permeation into the systemic circulation is minimal as evidenced from pharmacokinetic studies in human volunteers and patients with tinea pedis $[36,41,45,46]$. Twenty healthy volunteers were randomized to receive terbinafine $1 \%$ cream applied to the upper back as a single dose, or once daily for 3, 5 or 7 consecutive days [41]. Using the back as a model system for pharmacokinetic analysis of the skin is state of the art, and the data are transferable to those relevant to the skin of the foot as the skin is structured similarly [47, 48]. For HPLC analysis, up to 5 sequential skin surface biopsies were taken from the treatment areas, both during the application period and thereafter. Increasing the number of applications from 1 to 7 did not significantly augment the peak concentration in the stratum corneum (about $1 \mu \mathrm{g} / \mathrm{cm}^{2}$ from day 1 to 7). However, terbinafine was detectable for 7 days after cessation. After a 7-day application of terbinafine 1\% cream, the biphasic elimination pattern of terbinafine from the stratum corneum (with a rapid decline over the first $12 \mathrm{~h}$ ) showed a 3 times longer elimination half-life as compared to a single application. Moreover, the drug levels significantly exceed the minimum fungicidal concentrations of most of the dermatophyte strains during the treatment course and at least 100 -fold for 7 days following the last application [41].

Long-lasting terbinafine concentrations in the skin with just a single application inspired the development of a formulation for single-dose therapy in patients with tinea pedis. This became a reality using an FFS containing terbinafine $1 \%$, ethanol and a bioadhesive acrylate/acrylamide copolymer matrix. Ethanol evaporates rapidly after the application of this FFS on the skin. The high concentration gradient results in pronounced terbinafine skin penetration, which is further facilitated by the alcohol [49-51]. Moreover, the adhesion of the polymer matrix inhibits the removal of terbinafine from the skin surface and thus induces an ongoing absorption process for an additional few days - in the absence of early skin washing within the first $24 \mathrm{~h}$ after application [36].

Terbinafine binds to corneocytes and remains there for a long period as demonstrated by a recent study in 36 healthy subjects who applied terbinafine 1\% FFS and cream on their back [36]. Eleven consecutive tape strips were taken from defined treatment areas at baseline and 1-312 $\mathrm{h}$ after application for drug determination by liquid chromatography/mass spectroscopy. The drug amounts recovered by the tape strips were reported. Peak amounts in the stratum corneum following a single dose of both cream and FFS were obtained already at about $1.5-2 \mathrm{~h}$, yet the amounts obtained with the FFS $(5.0 \mu \mathrm{g} /$ $\mathrm{cm}^{2}$ ) surpassed the peak value reached with the cream $\left(2.0 \mu \mathrm{g} / \mathrm{cm}^{2}\right)$ by $>2$-fold. The average $\mathrm{AUC}_{0-168 \mathrm{~h}}$ (area under the concentration time curve) reflecting total drug within the horny layer over 7 days increased by 3 -fold (table 1). When considering the entire dosing regimen, the average $\mathrm{AUC}_{0-312 \mathrm{~h}}$ with a single dose of terbinafine $1 \%$ FFS was $84 \%$ of the exposure obtained with 7 days of cream treatment (table 1). In other words, terbinafine stratum corneum exposure $\left(\mathrm{AUC}_{0-312 \mathrm{~h}}\right)$ after single-dose treatment with FFS was nearly equivalent to 6 applications with terbinafine cream [36]. With the FFS, 30\% of the total drug delivered into the stratum corneum occurred during the first $2 \mathrm{~h}, 31 \%$ from $2-12 \mathrm{~h}$ and $39 \%$ thereafter. Furthermore, $75 \%$ of the penetrated drug was 


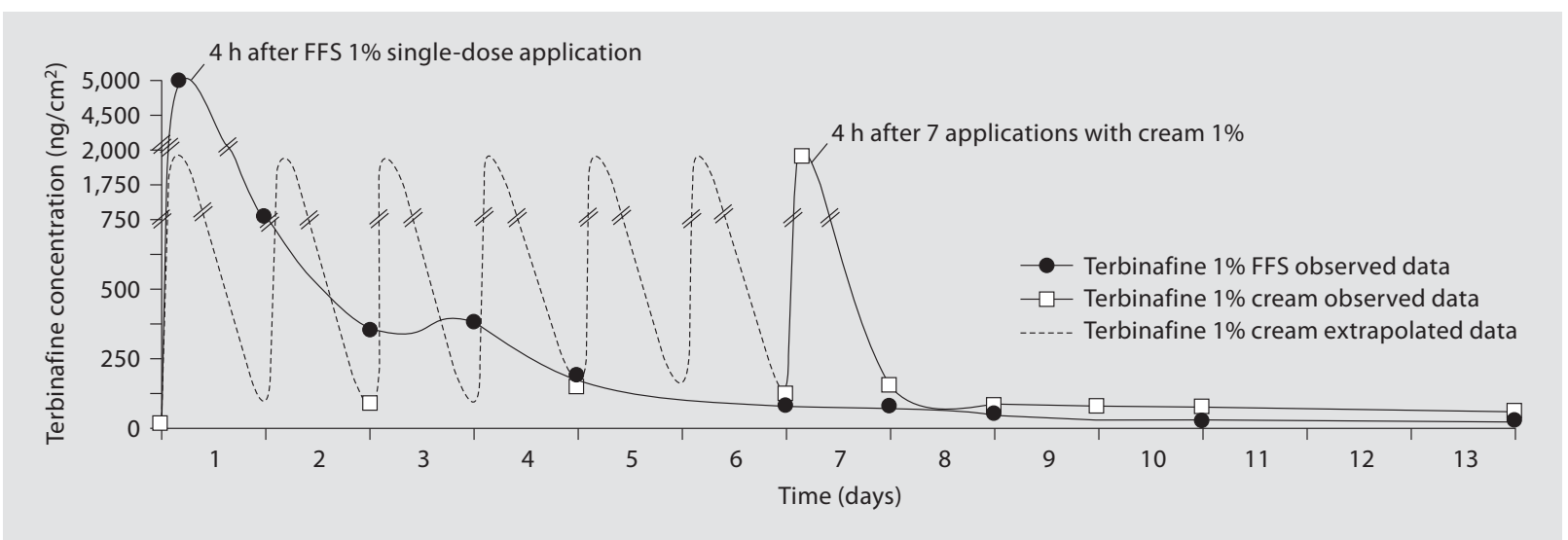

Fig. 2. Terbinafine $1 \%$ FFS ( $50 \mu \mathrm{g} / \mathrm{cm}^{2}$ terbinafine) allows higher terbinafine concentrations in the stratum corneum as compared to the cream, yielding a 'fungicidal reservoir effect' over 13 days [9-11,36].

within the outermost horny layer (strips 1-6) and $25 \%$ in the deeper layers (strips 7-11). The respective elimination half-life was $162 \mathrm{~h}$ for FFS and $68 \mathrm{~h}$ for the cream (table 1). The elimination half-life for the cream is consistent with earlier results [39, 41]. The terbinafine skin levels of 24 $\mathrm{ng} / \mathrm{cm}^{2}$ at 13 days after a single application of the FFS were close to those seen 7 days after the final cream application and exceeded the in vitro fungicidal concentrations for dermatophytes ([9-11, 36], fig. 2).

Overall, the pharmacokinetic study demonstrates the superior skin pharmacokinetic profile of terbinafine using the FFS. Interestingly, another film-forming formulation based on a hydroxypropyl chitosan lacquer which allowed close contact and strong adhesion to the keratin matrix also increased ciclopirox penetration into thin membranes obtained from bovine hooves [52]. This underscores the potential of bioadhesive films for drug delivery in dermatotherapy.

Systemic exposure of terbinafine following topical application of $1 \%$ cream or $1 \%$ FFS was found to be very low both in healthy volunteers and in patients with dermatomycoses, i.e. tinea pedis or pityriasis versicolor. When applied for $8 \mathrm{~h}$ on skin with or without a reduced barrier function and with or without occlusion, terbinafine $1 \%$ cream resulted in a plasma concentration of $11.4 \mathrm{ng} / \mathrm{ml}$. This approximates about $1 \%$ of the exposure following oral administration of a $250-\mathrm{mg}$ tablet. A reduced barrier function did not result in higher values [46]. There was no evidence of increased systemic exposure with longterm application of terbinafine, since the maximum plasma concentration observed in patients with pityriasis versicolor treated twice daily for 28 days showed similar results $(24.8 \mathrm{ng} / \mathrm{ml})$ [46]. In 20 healthy volunteers, an application of 3 times the proposed therapeutic dose of terbinafine $1 \%$ FFS $\left(0.05 \mathrm{mg}\right.$ terbinafine $\left./ \mathrm{cm}^{2}\right)$ resulted in blood exposure to terbinafine of $<0.5 \%$ of the exposure following oral administration of a 250 -mg tablet [36]. In 14 patients with tinea pedis, a plasma level of terbinafine $>1 \mathrm{ng} / \mathrm{ml}$ was measured in only 1 sample [36].

The very low systemic absorption of terbinafine observed following topical application in healthy volunteers and patients with cutaneous fungal infections confirms the systemic safety and suggests that the stratum corneum acts as both a barrier and a reservoir for the lipophilic terbinafine and that systemic absorption is not affected by the integrity or inflammation of the stratum corneum.

\section{Skin Pharmacokinetics of Other Antifungals}

Other antifungal agents also accumulate in high concentrations in horny layers of the skin. Following topical occlusive application of $1 \%$ bifonazole or $1 \%$ clotrimazole cream (5 $\mathrm{mg}$ active agent, respectively) on the back of healthy volunteers, the half-lives of bifonazole retained in the horny layer ranged from 19 to $32 \mathrm{~h}$ and were nearly similar to those of clotrimazole. The quantity of bifonazole in the skin, however, was about twice as high as that of clotrimazole [48]. When applied under occlusive conditions as $1 \%$ solution or $1 \%$ cream (15 mg bifonazole) on the skin of volunteers with a contact time of $12 \mathrm{~h}$, the bifonazole concentrations in the stratum corneum exceeded the minimum inhibitory concentration for most of the dermatophytes [53]. 
The results of studies in the guinea pig are in accordance - fluconazole, itraconazole and griseofulvin build up high intracutaneous concentrations after oral or topical once-daily application and remain there for a certain period, e.g. up to 4 days for miconazole [54, 55]. However, the concentrations of itraconazole and ketoconazole in the stratum corneum are low compared to those of terbinafine and fluconazole (at least after oral application) [56].

As with terbinafine, the systemic absorption of topically applied azoles is low. In healthy volunteers, a single topical application of bifonazole as a $1 \%$ cream or a $1 \%$ solution with or without occlusion yielded bifonazole plasma levels $<1 \mathrm{ng} / \mathrm{ml}$, representing approximately $<1 \%$ of the applied amount; repeated applications did not lead to levels exceeding $5 \mathrm{ng} / \mathrm{ml}$ [53]. Similar results were obtained with topically applied clotrimazole and miconazole, $<2 \%$ of the applied amount of these antifungal agents became systemically available $[57,58]$. Systemic absorption of bifonazole was affected by inflammation of the skin, since the absorbed amount increased by up to 4 fold when applied on damaged skin [for review see 53].

Binding of antifungal agents to keratin [54, 59] decreases their in vitro antifungal activity $[54,60]$, but this binding is generally weak and reversible and hence can prolong retention in the skin [44]. In summary antifungal agents other than terbinafine also accumulate in high concentrations in horny layers of the skin, however, they require a longer duration of treatment to be efficacious probably because of their fungistatic mode of action.

\section{Effectiveness due to Fungicidal Activity and Reservoir Effect}

The accumulation in the stratum corneum is described for many lipophilic drugs including terbinafine, azole antifungals and glucocorticoids. The concentration of the active ingredient in the horny layer and the very slow elimination of the drug from this site play an important role in providing a long-term effect of terbinafine with continued increase in cure rates even after cessation of application. In fact, elimination from the stratum corneum is most likely more closely linked to the physiological skin turnover than to absorption into the blood stream.

As a reservoir effect is not only seen with terbinafine but has also been described for azole antifungal drugs [52-55, 61-64], the improved efficacy of terbinafine in managing cutaneous fungal infections (especially when caused by dermatophytes) may be due to the combination of accumulation in the horny layer and its potent fungicidal mode of action. As the minimum fungicidal concentrations of terbinafine against dermatophytes are very low compared to the azole antifungals, terbinafine probably exerts its antifungal activity as long as the drug is detectable in the skin. At the same time the terbinafine plasma concentrations are clearly below the skin levels in healthy volunteers and in patients with hyperkeratotic tinea pedis $[36,41,45]$. This leads to a notably long-lasting fungicidal action beyond the treatment period in the skin. In summary, the combination of reservoir effect and fungicidal activity of terbinafine even at low concentrations allows a 1-week treatment with cream, gel and spray solution, or just a single-application treatment with the new FFS formulation.

\section{Conclusion}

The pronounced fungicidal effect of terbinafine plus the accumulation within and slow elimination from the stratum corneum, in other words the reservoir effect of the drug, in principle make short-term therapy with terbinafine for tinea pedis feasible - either as once-daily 7day treatment with cream or a single-dose treatment using the FFS. The FFS ensures skin contact for a sufficiently long time and provides a high concentration gradient favoring terbinafine penetration into the horny layer, which is the site of dermatophyte infection. Thus, a highly active pharmaceutical agent coupled with a distinct reservoir effect facilitated by the characteristics of the vehicle are very important for an efficacious and convenient therapy. The new terbinafine FFS looks particularly apt to allow a single-dose therapy of tinea pedis.

References

$$
\begin{aligned}
& 1 \text { Evans EG: Tinea pedis: clinical experience } \\
& \text { and efficacy of short treatment. Dermatolo- } \\
& \text { gy 1997;194(suppl 1):3-6. } \\
& 2 \text { Birnbaum JE: Pharmacology of the allyl- } \\
& \text { amines. J Am Acad Dermatol 1990;23:782- } \\
& 785 \text {. } \\
& 3 \text { Aste N, Pau M, Aste N, Biggio P: Tinea pedis } \\
& \text { observed in Cagliari, Italy, between } 1996 \text { and } \\
& \text { 2000. Mycoses 2003;46:38-41. } \\
& 4 \text { Kemna ME, Elewski BE: A US epidemiologic } \\
& \text { survey of superficial fungal diseases. J Am } \\
& \text { Acad Dermatol 1996;35:539-542. } \\
& 5 \text { Maruyama R, Hiruma M, Yamauchi K, Tera- } \\
& \text { guchi S, Yamaguchi: An epidemiological and } \\
& \text { clinical study of untreated patients with tin- } \\
& \text { ea pedis within a company in Japan. Mycoses } \\
& \text { 2003;46:208-212. }
\end{aligned}
$$


6 Summerbell RC, Kane J, Krajden S: Onychomycosis, tinea pedis and tinea manuum caused by non-dermatophytic filamentous fungi. Mycoses 1989;32:609-619.

7 McClellan KJ, Wiseman LR, Markham A: Terbinafine: an update of its use in superficial mycoses. Drugs 1999;58:179-202.

8 Schmid-Wendtner M-H: Terbinafin. Systemische und topische Therapie von Pilzinfektionen; in Schäfer-Korting M (ed): The Critical Drug Monograph. Berlin, ABW Wissenschaftsverlag, 2006.

9 Korting HC, Ollert M, Abeck D; German Collaborative Dermatophyte Drug Susceptibility Study Group: Results of German multicenter study of antimicrobial susceptibilities of Trichophyton rubrum and Trichophyton mentagrophytes strains causing tinea unguium. Antimicrob Agents Chemother 1995;39:1206-1208.

10 Ryder N, Favre B: Antifungal activity and mechanism of action of terbinafine. Rev Contemp Pharmacother 1997;8:275-287.

11 Schuster I, Schaude M, Schatz F, Mieth H: Preclinical Characteristics of allylamins; in Berg D, Plempel M (eds): Sterol Biosynthesis Inhibitors. Pharmaceutical and Agrochemical Aspects. Chichester, Ellis Horwood, 1988, pp 449-470.

12 Clayton YM: Relevance of broad-spectrum and fungicidal activity of antifungals in the treatment of dermatomycoses. Br J Dermatol 1994;130(suppl 43):7-8.

13 Korting HC, Kresimon J, Rychlik R: Comparative evaluation of the activity and clinical effectiveness of terbinafine and bifonazole preparations in the treatment of pedal mycosis. Akt Dermatol 2004;30:210-217.

14 Berman B, Ellis C, Leyden J, Lowe N, Savin R, Shupack J, Stiller M, Tschen E, Zaias N, Birnbaum JE: Efficacy of a 1-week, twicedaily regimen of terbinafine $1 \%$ cream in the treatment of interdigital tinea pedis: results of placebo-controlled, double-blind, multicenter trials. J Am Acad Dermatol 1992;26: 956-960.

15 Evans EG, James IG, Joshipura RC: Twoweek treatment of tinea pedis with terbinafine (Lamisil) 1\% cream: a placebo-controlled study. J Dermatolog Treat 1991;2: 95-97.

16 Korting HC, Tietz HJ, Bräutigam M, Mayser P, Rapatz G, Paul C; LAS-INT-06 Study Group: One week terbinafine $1 \%$ cream (Lamisil) once daily is effective in the treatment of interdigital tinea pedis: a vehiclecontrolled study. Med Mycol 2001;39:335340.

17 Lebwohl M, Elewski B, Eisen D, Savin RC: Efficacy and safety of terbinafine $1 \%$ solution in the treatment of interdigital tinea pedis and tinea corporis or tinea cruris. Cutis 2001;67:261-266.

18 Savin R: Treatment of chronic tinea pedis (athlete's foot type) with topical terbinafine. J Am Acad Dermatol 1990;23:786-789.
19 Savin R, Atton AV, Bergstresser PR, Elewski B, Jones HE, Levine N, Leyden J, Monroe A Pandya A, Shupack J: Efficacy of terbinafine $1 \%$ cream in the treatment of moccasin-type tinea pedis: results of placebo-controlled multicenter trials. J Am Acad Dermato 1994;30:663-667.

20 Hollmen KA, Kinnunen T, Kiistala U, Väänänen A, Saarelainen IO, de Cuyper C, Decroix J, Broeckx W, Karvonen J: Efficacy and tolerability of terbinafine $1 \%$ emulsion gel in patients with tinea pedis. J Eur Acad Dermatol Venerol 2002;16:87-88.

21 Smith EB, Noppakun N, Newton RC: A clinical trial of topical terbinafine (a new allylamine antifungal) in the treatment of tinea pedis. J Am Acad Dermatol 1990;23:790794.

22 Korting HC, Rychlik R, Pfeil B: Treatment of interdigital tinea pedis. Dtsch Med Wochenschr 2003;128:1819-1824.

23 Hart R, Bee-Syer SEM, Crawford F, Torgerson DJ, Young P, Russell I: Systematic review of topical treatments for fungal infections of the skin and nails of the feet. BMJ 1999;319: $79-82$.

24 Wahid Z, Butt J, Nishtar R: Multicentre double-blind study of efficacy and safety of terbinafine $1 \%$ cream compared with bifonazole $1 \%$ cream in patients with tinea pedis moccasin type. J Dermatolog Treat 1997;8: 225-227.

25 Ablon G, Rosen T, Spedale J: Comparative efficacy of naftifine, oxiconazole, and terbinafine in short-term treatment of tinea pedis. Int J Dermatol 1996;35:591-593.

26 Bergstresser PR, Elewski B, Hanifin J, Lesher J, Savin R, Shupack J, Stiller M, Tschen E, Zaias N, Birnbaum JE: Topical terbinafine and clotrimazole in interdigital tinea pedis: a multicenter comparison of cure and relapse rates with 1- and 4-week treatment regimens. J Am Acad Dermatol 1993;28:648-651.

27 Evans EG, Dodman B, Williamson DM Brown GJ, Bowen RG: Comparison of terbinafine and clotrimazole in treating tinea pedis. BMJ 1993;307:645-647.

28 Patel A, Brookman SD, Bullen MU, Marley J, Ellis DH, Williams T, Barnetson RS: Topical treatment of interdigital tinea pedis: terbinafine compared with clotrimazole. Aust J Dermatol 1999;40:197-200.

29 Vermeer BJ, Staats CCG, van Houwelingen JC: Terbinafine versus Miconazol bij patienten met tinea pedis. Ned Tijdschr Geneeskd 1996;31:1605-1608.

30 Schopf R, Hettler O, Bräutigam M, et al: Efficacy and tolerability of terbinafine $1 \%$ topical solution used for 1 week compared with 4 weeks clotrimazole $1 \%$ topical solution in the treatment of interdigital tinea pedis: a randomized, double-blind, multi-centre, 8 week clinical trial. Mycoses 1999;42:415420 .
31 Leenutaphong V, Tangwiwat S, Muanprasat C, Niumpradit N, Sritaveesuwan R: Doubleblind study of the efficacy of 1 week topical terbinafine cream compared to 4 weeks miconazole cream in patients with tinea pedis. J Med Assoc Thai 1999;82:1006-1010.

32 Sanchez Carazo JL, Fuente C, Oliver V, Umbert P: Estudio Miconazol crema al $1 \%$ en aplicación única diaria en tiña pedis. Actas Dermosifiliogr 1994;85:388-394.

33 Chauvin MF, Viguié-Vallanet C, Kienzler JL, Larnier C: Novel, single-dose, topical treatment of tinea pedis using terbinafine: results of a dose-finding clinical trial. Mycoses 2008;51:1-6.

34 Ortonne JP, Korting HC, Viguié-Vallanet C, Larnier C, Savaluny E: Efficacy and Safety of a novel single-dose topical terbinafine formulation in patients with tinea pedis (athlete's foot): a randomized, double-blind placebo-controlled study. J Eur Acad Dermatol Venerol 2006;20:1307-1313.

35 Korting HC, Kiencke P, Rychlik R: Terbinafine for the topical treatment of tinea pedis: meta-analysis of published RCT: efficacy and safety. Poster presentation, 15th Congr Eur Acad Dermatol Venereol, Rhodes, October 4-8, 2006.

36 Kienzler J-L, Queille-Roussel C, Mugglestone C, Ortonne J-P, Larnier C: Skin pharmacokinetics of the antifungal drug, terbinafine, in a novel formulation called film forming solution (FFS), for a single-dose application in dermatophytoses. Curr Med Res Opin 2007;6:1293-1302.

37 Savin RC, Zaias N: Treatment of chronic moccasin-type tinea pedis with terbinafine: a double-blind, placebo-controlled trial. J Am Acad Dermatol 1990;23:804-807.

38 Faergemann J, Zehender H, Denouel J, Millerioux L: Levels of terbinafine in plasma, stratum corneum, dermis-epidermis (without stratum corneum), sebum, hair and nails during and after $250 \mathrm{mg}$ terbinafine orally once per day for four weeks. Acta Derm Venereol 1993;73:305-309.

39 Faergemann J, Zehender H, Jones T, Maibach I: Terbinafine levels in serum, stratum corneum, dermis-epidermis (without stratum corneum), hair, sebum and eccrine sweat. Acta Derm Venereol 1991;71:322326.

40 Finlay AY: Pharmacokinetics of terbinafine in the nail. Br J Dermatol 1992;126(suppl 39):28-32.

41 Hill S, Thomas R, Smith SG, Finlay AY: An investigation of the pharmacokinetics of topical terbinafine (Lamisil) 1\% cream. Br J Dermatol 1992;127:396-400.

42 Hosseini-Yeganeh M, McLachlan AJ: Tissue distribution of terbinafine in rats. J Pharm Sci 2001;90:1817-1828.

43 Hosseini-Yeganeh M, McLachlan AJ: Physiologically based pharmacokinetic model for terbinafine in rats and humans. Antimicrob Agents Chemother 2002;46:2219-2228. 
44 Uchida K, Yamaguchi H: Studies on the affinity of terbinafine with keratin. Jpn J Med Mycol 1993;34:207-212.

45 Tanuma H, Doi M, Ohta Y, Nishiyama S, Katsuoka K, Kaneko S, Mukai H, Abe M: Usefulness of $1 \%$ terbinafine $\mathrm{HCl}$ (Lamisil) cream for hyperkeratotic-type tinea pedis and its transfer into the horny layer. Mycoses 2000;43:417-432.

46 Dykes PJ, Thomas R, Lever L, Marks R: Pharmacokinetics of topically applied terbinafine: results from studies in healthy volunteer subjects and patients with pityriasis versicolor. J Dermatolog Treat 1990;1:1921.

47 Surber C, Schwarb FP, Smith EW: Tapestripping technique. J Toxicol Cutaneous Ocul Toxicol 2001;20:461-474.

48 Lücker PW, Beubler E, Kukovetz WR, Ritter $\mathrm{W}$ : Retention time and concentration in human skin bifonazole and clotrimazole. Dermatologica 1984;169(suppl 1):51-56.

49 Finnin BC, Morgan TM: Transdermal penetration enhancers: applications, limitations, and potential. J Pharm Sci 1999;88: 955-958.

50 Alberti I, Kalia YN, Naik A, Bonny JD, Guy $\mathrm{RH}$ : In vivo assessment of enhanced topical delivery of terbinafine to human stratum corneum. J Control Release 2001;7:319-327.
51 Alberti I, Kalia YN, Naik A, Guy RH: Assessment and prediction of the cutaneous bioavailability of topical terbinafine in vivo in man. Pharm Res 2001;18:1472-1475.

52 Monti D, Saccomani L, Chetoni P, Burgalassi S, Saettone MF, Mailland F: In vitro transungual permeation of ciclopirox from a hydroxypropyl chitosan-based, water-soluble nail lacquer. Drug Dev Ind Pharm 2005; 31:11-17.

53 Ritter W, Siefert HM: Biological disposition and percutaneous absorption of bifonazole in animals and man; in Fromtling RA (ed): Recent Trends in the Discovery, Development and Evaluation of Antifungal Agents. Barcelona, Prous Science Publishers, 1987, pp 383-405.

54 Sobue S, Sekiguchi K, Nabeshima T: Intracutaneous distribution of fluconazole, itraconazole, and griseofulvin in Guinea pigs and binding to human stratum corneum. Antimicrob Agents Chemother 2004;48:216223.

55 Pershing LK, Corlett J, Jorgensen C: In vivo pharmacokinetics and pharmacodynamics of topical ketoconazole and miconazole in human stratum corneum. Antimicrob Agents Chemother 1994;38:90-95.

56 Faergemann J: Pharmacokinetics of terbinafine. Rev Contemp Pharmacother 1997;8: 289-297.
57 Patschke K, Wegner LA, Oberste-Lehn H, Horster FA: Pharmakokinetische Untersuchungen nach topischer Anwendung von Clotrimazol (Canesten). Münch Med Wochenschr 1976;118(suppl 1):12-15.

58 Degreef $\mathrm{H}$, Heeres J, Borgers M: Antifungal azoles for skin disorders. Expert Opin Ther Pat 2006;16:1235-1253.

59 Klimke K, Schäfer-Korting M: Einfluss von Keratin auf die Wirksamkeit von Fluconazol. Mycoses 1997;40(suppl 1):43-46.

60 Tomura A, Takahashi S: Experimental study on pharmacokinetic action of topical antifungal agents in the human stratum corneum. Jpn J Med Mycol 1995;36:149-156.

61 Haneke E: Retention of ketoconazole in the skin following oral treatment. Hautarzt 1987;38:93-96.

62 Faergemann J, Laufen H: Levels of fluconazole in normal and diseased nails during and after treatment of onychomycoses in toe-nails with fluconazole $150 \mathrm{mg}$ once weekly. Acta Derm Venereol 1996;76:219221.

63 Kawada A, Aragane Y, Tezuka T: Clinical and pharmacokinetic studies of continuous itraconazole for the treatment of onychomycosis. J Dermatol 2004;31:104-108.

64 Leyden J: Pharmacokinetics and pharmacology of terbinafine and itraconazole. J Am Acad Dermatol 1998;38:S42-S47. 